International Journal of Child, Youth and Family Studies (2013) 1: 166-188

\title{
ETHNIC DIVERSITY AND YOUTH OFFENDING: AN EXAMINATION OF RISK AND PROTECTIVE FACTORS
}

\section{Lorne D. Bertrand, Leslie D. MacRae-Krisa, Meghan Costello, and John Winterdyk}

\begin{abstract}
This study examined risk and protective factors for criminal reoffending behaviour among a group of Canadian young people who had committed at least one substantive criminal offence in the past and fell into one of four ethnic groups: (a) Canadian born, parents Canadian born; (b) Aboriginal/Métis; (c) first or second generation immigrant, Caucasian; and (d) first or second generation immigrant, other ethnic background. Risk and protective factors were classified into five domains: individual; family; peer; school; and community. Consistent with previous research, the findings did not reveal many instances where statistically significant differences existed in the presence of risk and protective factors across ethnic groups; however, significant differences that were observed were across a wide range of variables. The implications of the findings within the context of previous research in this area are discussed.
\end{abstract}

Keywords: youth offending, ethnic diversity, risk factors, protective factors

Acknowledgements: This research was funded by the Centre for Criminology and Justice Research at Mount Royal University, the Alberta Law Foundation, and the City of Calgary.

Lorne D. Bertrand, Ph.D. is Senior Research Associate at the Canadian Research Institute for Law and the Family, University of Calgary, Suite 510, 1816 Crowchild Trail NW, Calgary, Alberta, Canada, T2M 3Y7. E-mail: lbertran@ucalgary.ca

Leslie D. MacRae-Krisa, M.A. (the Corresponding Author) is Coordinator of Alberta-based Research Projects at the Canadian Research Institute for Law and the Family, University of Calgary, Suite 510, 1816 Crowchild Trail NW, Calgary, Alberta, Canada, T2M 3Y7. E-mail: ldmacrae@ucalgary.ca

Meghan Costello is a student in the Justice Studies Program at Mount Royal University, 4825 Mount Royal Gate SW, Calgary, Alberta, Canada, T3E 6K6. Email: mcost606@mymru.ca

John Winterdyk, Ph.D. is a professor in the Department of Justice Studies, Mount Royal University, 4825 Mount Royal Gate SW, Calgary Alberta, Canada, T3E 6K6. Telephone: (403) 440-6992. E-mail: JWinterdyk@mtroyal.ca 
International Journal of Child, Youth and Family Studies (2013) 1: 166-188

The Government of Alberta's (2011) Crime Prevention Framework identifies risk factors as personal or environmental conditions that increase an individual's chances for criminal involvement. Protective factors are identified as factors that improve an individual's life while reducing the risk for criminal involvement. Given the unique challenges faced by immigrant, refugee, and Aboriginal youth, variations in risk and protective factors are expected among Canadian youth offenders belonging to these ethnic backgrounds. However, as discussed by Wortley (2003), information and research on ethnic minorities in Canada is difficult to obtain due to Canada's “informal ban on the release of race-based crime statistics” (p. 101). Canadian research in this area, particularly research comparing the risk and protective factors among different ethnicities, is scarce making it difficult to achieve a Canadian-based perspective on the factors leading minority youth to criminal involvement.

The Alberta Crime Reduction and Safe Communities Task Force (2007) identified the following five major risk and protective domains that are important to consider when examining offending behaviour among youth: individual; family; peer; school; and community. Factors in the individual domain include demographic characteristics, attitudes toward crime, history of deviant behaviour, substance abuse, aggression, impulsivity, and mental health issues. Included in the family factors domain are the presence of familial criminality, family violence, family management and supervision, and family breakdown. Factors in the peer domain include degree of involvement in pro-social extracurricular activities, peer association, and gang involvement. The school domain includes factors related to school attendance, behaviour, and achievement, and the community domain considers level of community attachment and organization.

\section{Risk Factors Among Aboriginal Youth}

Substance abuse has been identified as an individual risk factor that is predominant among youth offenders. As Choi, Harachi, Gillmore, and Catalano (2005) observe: "substance abuse has been found to be associated with violence, delinquency, academic underachievement, and school problems” (p. 506). Research suggests that there is a particularly high rate of substance abuse among Aboriginal youth offenders (Rojas \& Gretton, 2007; Yessine \& Bonta, 2009) and that offending patterns seem to be affected by increased alcohol or drug use (Bonta, LaPrairie, \& Wallace-Capretta, 1997). Furthermore, the presence of Fetal Alcohol Spectrum Disorder (FASD) in the Aboriginal population is another individual risk factor that is highlighted by Rojas and Gretton (2007).

Family and community factors also play a major role in the lives of most Aboriginal youth. Rojas and Gretton (2007) list a number of family and community factors that increase the risk of criminal involvement for Aboriginal youth. There is a significant likelihood of Aboriginal youth being subject to high rates of child abuse in their homes and communities, while also growing up with unstable living conditions. Due to the close-knit structure of Aboriginal families and communities (particularly for those who live on reserves), child abuse is a sensitive matter that is often not properly dealt with because of perceived repercussions and negative sentiment from the community (Rojas \& Gretton, 2007). High rates of caregiver inconsistency have also been suggested as a risk factor (Rojas \& Gretton, 2007; Yessine \& Bonta, 2009). On average, Aboriginal youth are likely to experience at least three changes in their primary caregivers during childhood. However, there are no findings that suggest that this is a significant detriment to 
International Journal of Child, Youth and Family Studies (2013) 1: 166-188

Aboriginal youth (Rojas \& Gretton, 2007). While Western culture would state that inconsistent living conditions are a risk factor for youth, Aboriginal culture emphasizes reliance on extended family and community members. Thus, having multiple caregivers may be a sign of strong familial and communal support rather than a risk factor for Aboriginal youth.

When evaluating the risk factors that are specific to Aboriginal youth, the history of Aboriginal people in Canada cannot be overlooked. The residential schools that were put in place by the Government of Canada in the 19th and 20th centuries caused disconnect between Aboriginal people, their culture, and their families. Bracken, Deane, and Morrissette (2009) suggest that the intergenerational trauma that resulted from the residential schools era, combined with racism and structural barriers - for example, poor housing, negative stereotypes, and poor educational opportunities - often result in marginalization among Aboriginal youth. The peer support, interaction, status, and protection that gangs provide make gang involvement an attractive option for those who are struggling with self-identity and are having difficulty connecting with their Aboriginal culture (Bracken et al., 2009).

School and educational risk factors are also apparent among Aboriginal youth offenders. Rojas and Gretton (2007) state that Aboriginal youth are: "on average, between two and three years below their academic education” (p. 274). Additionally, Aboriginal youth typically achieve a lower level of education when compared to non-Aboriginal youth (Bonta et al., 1997; Rojas \& Gretton, 2007). Also highlighted is the increased likelihood for Aboriginal youth to have a learning disability or mental disability limiting their ability to achieve higher education (Rojas \& Gretton, 2007).

\section{Protective Factors for Aboriginal Youth}

Discussions of protective factors for Aboriginal youth have been oriented toward addressing those factors perceived as risk factors. For instance, while research suggests that a highly influential individual risk factor among Aboriginal youth is substance abuse, reducing substance use and misuse among Aboriginal youth may, in turn, reduce the likelihood of criminal involvement.

In addition, while Rojas and Gretton (2007) state that caregiver inconsistency and life instability are generally associated with an increased risk for criminal involvement, it may be that multiple caregivers are a protective factor among Aboriginal youth. Though it remains unknown whether having multiple caregivers is a risk or protective factor, the value placed on the role of the extended family in Aboriginal communities could support the latter.

Regarding school and educational factors, Rojas and Gretton (2007) stress the importance of addressing individual challenges in order to adapt lessons to help youth achieve academic success. Given the high incidence of learning disabilities, mental health issues, and FASD among Aboriginal youth offenders, a specialized approach to ensuring educational success is essential.

Choi et al. (2005) suggest that increasing positive relationships within each of the five domains for risk and protective factors - individual, family, peer, school, and community - will improve the sense of belonging and identity among individuals, and reduce the likelihood of 
International Journal of Child, Youth and Family Studies (2013) 1: 166-188

criminal involvement. This is particularly true for Aboriginal youth offenders who are involved with gangs. Bracken et al. (2009) describe a United Way program in Winnipeg, Manitoba that aims to help gang-involved Aboriginals stop their criminal lifestyles while still maintaining their sense of pride and belonging. Ogijiita Pimatiswin Kinamatwin (OPK) is a program working with gang members newly released from custody, "who wish to leave the criminal activity of the gang, but without necessarily leaving the gang” (Bracken et al., 2009, p. 68). OPK provides work experience and educational/counselling sessions to each participant to help them establish a "legitimate lifestyle" while they continue to discover their cultural identity.

\section{Risk and Protective Factors Among Immigrant and Refugee Youth}

For the purposes of this study, immigrant youth were defined as first and second generation immigrants or refugees who were either born in another country and moved to Canada (first generation), or whose parents were born in another country and moved to Canada before having their children (second generation). A small body of Canadian literature has examined risk and protective factors among immigrant groups.

\section{Risk Factors for Immigrant Youth}

Previous research suggests that individual risk factors are very dependent on where an individual youth has immigrated from. Many immigrants, as described by Wortley (2003), do not understand Canada's justice system and end up unintentionally in conflict with the law (Rossiter \& Rossiter, 2009). Additional individual factors that Rossiter and Rossiter (2009) have identified include: "poor interpersonal skills, the use of violence to solve problems...a lack of personal and cultural identity, and a sense of powerlessness and hopelessness” (p. 417).

Family poverty is a substantial risk factor for immigrant youth in Canada. Many parents of immigrant families work multiple jobs in order to support their families, resulting in a lack of supervision of their children (Goodman \& Ruggiero, 2008; Rossiter \& Rossiter, 2009). There is also a high rate of addiction (e.g., to alcohol, drugs, and gambling) and family or domestic violence among new immigrants (Rossiter \& Rossiter, 2009). This unstable and unsupervised living environment often leads to youth involvement in criminal activity for financial gain and, subsequently, lower school attendance and achievement (Rossiter \& Rossiter, 2009). Similarly, living in an impoverished community is also viewed as a risk factor for these immigrant youth (Goodman \& Ruggiero, 2008). Communities that are not well established to support multicultural populations leave immigrant youth with a lack of safe and affordable housing, limited after school programs, sports teams, and activities, and a lack of positive relationships and role models (Rossiter \& Rossiter, 2009).

While research does not support the statement that immigrant youth are more involved in criminal activity than non-immigrant youth, it does support the finding that immigrant youth are more susceptible to recruitment into gang involvement (Rossiter \& Rossiter, 2009). In fact, approximately $82 \%$ of gang members identify as visible minorities and as either first or second generation immigrants (Rossiter \& Rossiter, 2009). 
International Journal of Child, Youth and Family Studies (2013) 1: 166-188

Immigrant youth are faced with multiple challenges and new experiences every day, so much so that many immigrants set their education as a lower priority than other factors: "The academic challenges that immigrant children face are often exacerbated by individual, family, peer and community factors that may leave newcomer youth vulnerable to victimization or recruitment to engage in illegal activities” (Rossiter \& Rossiter, 2009, p. 412). English as a Second Language (ESL) students are more likely to fail to complete high school and drop out of school because they do not have access to the necessary supports (Goodman \& Ruggiero, 2008; Rossiter \& Rossiter, 2009). Many schools and teachers are ill-prepared to deal with ESL youth and the parents of these youth do not have the education or knowledge to assist them with homework (Rossiter \& Rossiter, 2009). Many youth end up falling through the cracks of the education system as a result (Goodman \& Ruggiero, 2008).

\section{Protective Factors for Immigrant Youth}

Some individual risk factors for immigrant or refugee youth stem from a lack of knowledge of the Canadian criminal justice system (Wortley, 2003). In order to address this risk factor, Wortley suggests that two steps be taken. First, potential immigrants should be educated about Canadian law as they proceed with their immigration application. Secondly, all recent immigrants should be informed and educated about how their cultural traditions and customs may lead to conflicts with the law (Wortley, 2003). Additionally, Rossiter and Rossiter (2009) state that immigrant youth who have a stronger sense of cultural identity and belonging have increased resilience and are less likely to engage in criminal activity. This sense of belonging may come from strong family and community ties or religious affiliation; a feeling of general acceptance from peers will also foster this sense of belonging (Rossiter \& Rossiter, 2009).

Rossiter and Rossiter (2009) further stress the importance of family and communities as protective factors for immigrant youth. Research suggests that youth who have strong family structure and who receive support, attention, and supervision from their parents and extended families are less likely to be involved in crime (Choi et al., 2005; Rossiter \& Rossiter, 2009). Similarly, involvement with church or community groups also acts as a protective factor for immigrant youth. Such involvement continues to foster a sense of belonging and purpose (Choi et al., 2005; Rossiter \& Rossiter, 2009).

Comparable to other protective factors, peer and school factors that are thought to limit the likelihood of criminal involvement in immigrant youth primarily relate to establishing a sense of belonging and providing support. Youth who engage in inter-cultural peer programs may be less at risk for involvement with the justice system (Rossiter \& Rossiter, 2009). In addition, youth who have educated parents who encourage school attendance and involvement in school activities are also less likely to come into contact with the justice system (Rossiter \& Rossiter, 2009).

Overall, protective factors for immigrant youth are strongly focused around education, belonging, and family or community involvement and support. Consistency and social acceptance of cultural differences also assist in limiting the likelihood of criminal involvement among immigrant youth (Choi et al., 2005; Rossiter \& Rossiter, 2009). 


\section{The Present Study}

The purpose of this project was to conduct an exploratory study of the similarities and differences in risk and protective factors for crime among an ethnically diverse sample of youth offenders. The project used data collected for a previous study on youth offending, serious habitual offenders, and justice system response in Calgary, Alberta (MacRae, Bertrand, Paetsch, Hornick, \& DeGusti, 2009) to identify unique risk and protective factors among Aboriginal youth, first and second generation immigrant and refugee youth, and other ethnic groups.

\section{Methodology}

\section{Participants}

A cohort of 103 youth in Calgary with various levels of involvement in the youth justice system was selected from the MacRae et al. (2009) study. Participants belonged to one of three offending groups:

\section{1. $\quad$ One-time Offenders $(n=42)$}

This group included youth having one substantive (i.e., Criminal Code; Controlled Drugs and Substances Act) offence or incident of which he or she had been found guilty ${ }^{1}$ (with no subsequent charges pending).

2. $\quad$ Chronic Offenders $(n=41)$

This group included youth having five or more substantive (i.e., Criminal Code, Controlled Drugs and Substances Act) offences or incidents of which he or she had been found guilty.

3. Serious Habitual Offenders (SHOs) $(n=20)$

Serious Habitual Offenders were identified through the Calgary Police Service's Serious Habitual Offender Program (SHOP). SHOP identifies youth at risk of a career of crime through a multidisciplinary resource team, and provides access to resources in order to help them be successful members of society. These youth are monitored regularly by the Calgary Police Service.

Using data available on country of birth, parents' country of birth, and ethnicity, the sample was categorized into the following groups: (a) Canadian born/parents Canadian born $(n=$ 52); (b) Aboriginal/Métis ( $n=15)$; (c) first or second generation immigrant (Caucasian) $(n=13)$; (d) first or second generation immigrant (other ethnic background) $(n=13)$. Some youth $(n=10)$ had missing data for some of these variables - two One-time Offenders, six Chronic Offenders, and two SHOs. Further exploration of these cases revealed that this was often due to the fact that these youth did not know one or both of their parents. Given that the purpose of this study was to draw comparisons among ethnic groups, these youth were removed from the sample. Therefore, the total sample size was 93. Due to the small sample size, data from the three offending groups were not analyzed separately.

\footnotetext{
${ }^{1}$ Incident was defined as all charges pertaining to the same person and having the same date of offence. Administration of justice incidents (e.g., breaches, failures to appear) were not counted as substantive incidents.
} 
International Journal of Child, Youth and Family Studies (2013) 1: 166-188

\section{Data Sources}

Life history interviews were conducted with all 93 youth between July 2006 and July 2007. Interview questions covered seven main topic areas: basic facts (i.e., demographic, familial); community (i.e., community characteristics, feelings of safety); school (i.e., school status, experience); social life (i.e., friends, activities, delinquency); offending history (i.e., contact with the criminal justice system); gangs (i.e., knowledge and experience of gangs in Calgary); and future (i.e., goals). The interviews were conducted in person at the City of Calgary Youth Probation Offices and the Calgary Young Offender Centre. Probation file reviews were conducted for each youth interviewed with the exception of one youth whose probation file could not be accessed. A probation file review form was developed following a preliminary examination of probation files. The form included demographic, familial, social, and offending information. File reviews were conducted at City of Calgary Youth Probation Offices.

\section{Results}

The relationship between the youths' ethnic background/immigration status and several factors related to the five domains identified in the literature (i.e., individual, family, peer group, school, and community) were examined. Statistical relationships between factors and ethnic background/immigration status were examined using Chi-square analyses; while statistically significant findings are highlighted, trends that were apparent but did not attain traditional significance levels are also discussed.

\section{Individual Factors Domain}

Several variables falling into the individual factors domain were examined to determine their relationship with immigration status. The majority of the youth in the sample were male (89.2\%). While there were no significant gender differences across the four immigration groups, the first or second generation immigrant, Caucasian group had the highest proportion of female youth (15.4\%), while the Native/Métis group had the lowest proportion of females (6.7\%). Across all groups, equal proportions of youth were employed at the time of the interview (49.5\%) and not employed (50.5\%). While not statistically significant, youth in the first or second generation immigrant, Caucasian group were least likely to be employed (30.8\%) and youth in the Canadian born/parents Canadian born group were most likely to be employed $(55.8 \%)$.

The relationship between alcohol- and drug-related variables and immigration status was also examined. The presence of substance abuse issues was significantly related to immigration status $\left(X^{2}(3)=16.2, p<.001\right)$. Over two-thirds of the total sample $(70.3 \%)$ reported having substance abuse issues. While over three-quarters of the youth in the Canadian born/parents Canadian born (78.4\%), Native/Métis (78.6\%), and first or second generation immigrant, Caucasian groups (76.9\%) had substance abuse issues, only $23.1 \%$ of youth in the first or second generation immigrant, other ethnic background group had substance abuse issues.

The majority of youth in all groups reported that they had had five or more alcoholic drinks on one occasion (94.6\%), had used illegal drugs (92.5\%), had bought illegal drugs 
International Journal of Child, Youth and Family Studies (2013) 1: 166-188

(83.9\%), and had sold illegal drugs (59.1\%). However, there were no significant differences between the various immigration groups on these behaviours.

Table 1. Ever Engaged in Property-related Delinquent Behaviour by Immigrant Status

\begin{tabular}{|c|c|c|c|c|c|c|c|c|c|c|}
\hline \multirow{3}{*}{ Delinquent Behaviour } & \multicolumn{8}{|c|}{ Immigrant Status } & \multicolumn{2}{|c|}{ Total } \\
\hline & \multicolumn{2}{|c|}{$\begin{array}{c}\text { Canadian } \\
\text { Born, } \\
\text { Parent(s) } \\
\text { Canadian } \\
\text { Born } \\
\end{array}$} & \multicolumn{2}{|c|}{ Native/Métis } & \multicolumn{2}{|c|}{$\begin{array}{l}1^{\text {st }} \text { or } 2^{\text {nd }} \\
\text { Generation } \\
\text { Immigrant, } \\
\text { Caucasian }\end{array}$} & \multicolumn{2}{|c|}{$\begin{array}{l}\mathbf{1}^{\text {st }} \text { or } 2^{\text {nd }} \\
\text { Generation } \\
\text { Immigrant, } \\
\text { Other Ethnic } \\
\text { Background } \\
\end{array}$} & \multirow[t]{2}{*}{$n$} & \multirow[t]{2}{*}{$\%$} \\
\hline & $n$ & $\%$ & $n$ & $\%$ & $n$ & $\%$ & $n$ & $\%$ & & \\
\hline $\begin{array}{l}\text { Damaged/Destroyed } \\
\text { Property on Purpose }\end{array}$ & & & & & & & & & & \\
\hline No & 11 & 21.2 & 3 & 20.0 & 4 & 30.8 & 7 & 53.8 & 25 & 26.9 \\
\hline Yes & 41 & 78.8 & 12 & 80.0 & 9 & 69.2 & 6 & 46.2 & 68 & 73.1 \\
\hline Total & 52 & 100.0 & 15 & 100.0 & 13 & 100.0 & 13 & 100.0 & 93 & 100.0 \\
\hline Broken into a House $^{2}$ & & & & & & & & & & \\
\hline No & 27 & 51.9 & 2 & 13.3 & 8 & 61.5 & 9 & 69.2 & 46 & 49.5 \\
\hline Yes & 25 & 48.1 & 13 & 86.7 & 5 & 38.5 & 4 & 30.8 & 47 & 50.5 \\
\hline Total & 52 & 100.0 & 15 & 100.0 & 13 & 100.0 & 13 & 100.0 & 93 & 100.0 \\
\hline $\begin{array}{l}\text { Ever Stolen Something } \\
\text { from a Place/Person }\end{array}$ & & & & & & & & & & \\
\hline No & 3 & 5.8 & 1 & 6.7 & 2 & 15.4 & 3 & 23.1 & 9 & 9.7 \\
\hline Yes & 49 & 94.2 & 14 & 93.3 & 11 & 84.6 & 10 & 76.9 & 84 & 90.3 \\
\hline Total & 52 & 100.0 & 15 & 100.0 & 13 & 100.0 & 13 & 100.0 & 93 & 100.0 \\
\hline $\begin{array}{l}\text { Stolen Something } \\
\text { Worth Less Than } \$ 50\end{array}$ & & & & & & & & & & \\
\hline No & 9 & 18.4 & 6 & 42.9 & 4 & 36.4 & 2 & 22.2 & 21 & 25.3 \\
\hline Yes & 40 & 81.6 & 8 & 57.1 & 7 & 63.6 & 7 & 77.8 & 62 & 74.7 \\
\hline Total & 49 & 100.0 & 14 & 100.0 & 11 & 100.0 & 9 & 100.0 & 83 & 100.0 \\
\hline $\begin{array}{l}\text { Stolen Something } \\
\text { Worth More Than } \$ 50\end{array}$ & & & & & & & & & & \\
\hline No & 11 & 22.4 & 2 & 14.3 & 5 & 45.5 & 2 & 22.2 & 20 & 24.1 \\
\hline Yes & 38 & 77.6 & 12 & 85.7 & 6 & 54.5 & 7 & 77.8 & 63 & 75.9 \\
\hline Total & 49 & 100.0 & 14 & 100.0 & 11 & 100.0 & 9 & 100.0 & 83 & 100.0 \\
\hline $\begin{array}{l}\text { Stolen Car or } \\
\text { Motorcycle }\end{array}$ & & & & & & & & & & \\
\hline No & 22 & 44.9 & 4 & 28.6 & 6 & 54.5 & 5 & 55.6 & 37 & 44.6 \\
\hline Yes & 27 & 55.1 & 10 & 71.4 & 5 & 45.5 & 4 & 44.4 & 46 & 55.4 \\
\hline Total & 49 & 100.0 & 14 & 100.0 & 11 & 100.0 & 9 & 100.0 & 83 & 100.0 \\
\hline $\begin{array}{l}\text { Stolen Something with } \\
\text { a Group of Friends }\end{array}$ & & & & & & & & & & \\
\hline No & 14 & 28.6 & 2 & 14.3 & 3 & 27.3 & 3 & 33.3 & 22 & 26.5 \\
\hline Yes & 35 & 71.4 & 12 & 85.7 & 8 & 72.7 & 6 & 66.7 & 61 & 73.5 \\
\hline Total & 49 & 100.0 & 14 & 100.0 & 11 & 100.0 & 9 & 100.0 & 83 & 100.0 \\
\hline
\end{tabular}

Source of data: Youth Offender Interview.

1 "Other Ethnic Background" includes Middle Eastern, Hispanic, African, Mulatto, and Asian.

${ }^{2} X^{2}(3)=10.7, p<.05$. 
International Journal of Child, Youth and Family Studies (2013) 1: 166-188

The proportions of youth who reported ever engaging in several property-related delinquent behaviours are shown in Table 1. Only one of these behaviours differed significantly across the four immigration status groups. One-half of all youth (50.5\%) had broken into a house; individuals in the Native/Métis group were most likely to have engaged in this behaviour (86.7\%), while youth in the first or second generation immigrant, other ethnic background group were least likely to have done this (30.8\%). Almost three-quarters of the overall sample (73.1\%) reported that they had damaged or destroyed someone's property on purpose. Almost all youth stated that they had ever stolen something from a place or person $(90.3 \%)$, with youth from the Canadian born/parents Canadian born group (94.2\%) and the Native/Métis group (93.3\%) most likely to have done this, and youth from the first or second generation immigrant, other ethnic background group least likely to have done this (76.9\%).

Just over one-half of all participants indicated that they had ever stolen a car or motorcycle (55.4\%); youth from the first or second generation immigrant, other ethnic background group (44.4\%) and the first or second generation immigrant, Caucasian group (45.5\%) were the least likely to have stolen a car or motorcycle while youth in the Native/Métis group were most likely to have done this (71.4\%). Almost three-quarters of all individuals (73.5\%) had stolen something with a group of friends.

Table 2 indicates the proportion of youth in each immigration status group who reported ever engaging in several person-related delinquent behaviours. None of these behaviours differed significantly across the groups; however, some patterns are worthy of note. Slightly over onehalf (53\%) of all youth indicated that they had taken or tried to take something from someone by force or threat of force; the proportion ranged from 33.3\% of youth in the first or second generation immigrant, other ethnic background group, to $64.3 \%$ of youth in the Native/Métis group. A substantial majority of all youth (83.9\%) reported that they had ever harassed, threatened, or bullied someone. 
International Journal of Child, Youth and Family Studies (2013) 1: 166-188

Table 2. Ever Engaged in Person-related Delinquent Behaviour by Immigrant Status

\begin{tabular}{|c|c|c|c|c|c|c|c|c|c|c|}
\hline \multirow{3}{*}{ Delinquent Behaviour } & \multicolumn{8}{|c|}{ Immigrant Status } & \multicolumn{2}{|c|}{ Total } \\
\hline & \multicolumn{2}{|c|}{$\begin{array}{c}\text { Canadian } \\
\text { Born, } \\
\text { Parent(s) } \\
\text { Canadian } \\
\text { Born }\end{array}$} & \multicolumn{2}{|c|}{ Native/Métis } & \multicolumn{2}{|c|}{$\begin{array}{l}1^{\text {st }} \text { or } 2^{\text {nd }} \\
\text { Generation } \\
\text { Immigrant, } \\
\text { Caucasian }\end{array}$} & \multicolumn{2}{|c|}{$\begin{array}{c}1^{\text {st }} \text { or } 2^{\text {nd }} \\
\text { Generation } \\
\text { Immigrant, } \\
\text { Other Ethnic } \\
\text { Background }\end{array}$} & \multirow[t]{2}{*}{$n$} & \multirow[t]{2}{*}{$\%$} \\
\hline & $n$ & $\%$ & $n$ & $\%$ & $n$ & $\%$ & $n$ & $\%$ & & \\
\hline $\begin{array}{l}\text { Taken/Tried to Take } \\
\text { Something by } \\
\text { Force/Threat of Force }\end{array}$ & & & & & & & & & & \\
\hline No & 23 & 46.9 & 5 & 35.7 & 5 & 45.5 & 6 & 66.7 & 39 & 47.0 \\
\hline Yes & 26 & 53.1 & 9 & 64.3 & 6 & 54.5 & 3 & 33.3 & 44 & 53.0 \\
\hline Total & 49 & 100.0 & 14 & 100.0 & 11 & 100.0 & 9 & 100.0 & 83 & 100.0 \\
\hline $\begin{array}{l}\text { Harassed, Threatened, } \\
\text { or Bullied Someone }\end{array}$ & & & & & & & & & & \\
\hline $\begin{array}{l}\text { No } \\
\text { Yes }\end{array}$ & $\begin{array}{r}9 \\
43\end{array}$ & $\begin{array}{l}17.3 \\
82.7\end{array}$ & $\begin{array}{r}1 \\
14\end{array}$ & $\begin{array}{r}6.7 \\
93.3\end{array}$ & $\begin{array}{l}4 \\
9\end{array}$ & $\begin{array}{l}30.8 \\
69.2\end{array}$ & $\begin{array}{r}1 \\
12\end{array}$ & $\begin{array}{r}7.7 \\
92.3\end{array}$ & $\begin{array}{l}15 \\
78\end{array}$ & $\begin{array}{l}16.1 \\
83.9\end{array}$ \\
\hline Total & 52 & 100.0 & 15 & 100.0 & 13 & 100.0 & 13 & 100.0 & 93 & 100.0 \\
\hline $\begin{array}{l}\text { Threatened Someone } \\
\text { with a Weapon }\end{array}$ & & & & & & & & & & \\
\hline No & 18 & 41.9 & 4 & 28.6 & 2 & 22.2 & 8 & 66.7 & 32 & 41.0 \\
\hline Yes & 25 & 58.1 & 10 & 71.4 & 7 & 77.8 & 4 & 33.3 & 46 & 59.0 \\
\hline Total & 43 & 100.0 & 14 & 100.0 & 9 & 100.0 & 12 & 100.0 & 78 & 100.0 \\
\hline $\begin{array}{l}\text { Assaulted or Hurt } \\
\text { Someone }\end{array}$ & & & & & & & & & & \\
\hline No & 8 & 15.4 & 2 & 13.3 & 2 & 15.4 & 0 & 0.0 & 12 & 12.9 \\
\hline Yes & 44 & 84.6 & 13 & 86.7 & 11 & 84.6 & 13 & 100.0 & 81 & 87.1 \\
\hline Total & 52 & 100.0 & 15 & 100.0 & 13 & 100.0 & 13 & 100.0 & 93 & 100.0 \\
\hline $\begin{array}{l}\text { Assaulted/Hurt } \\
\text { Someone with a } \\
\text { Weapon }\end{array}$ & & & & & & & & & & \\
\hline No & 18 & 41.9 & 4 & 30.8 & 4 & 36.4 & 5 & 38.5 & 31 & 38.8 \\
\hline Yes & 25 & 58.1 & 9 & 69.2 & 7 & 63.6 & 8 & 61.5 & 49 & 61.2 \\
\hline Total & 43 & 100.0 & 13 & 100.0 & 11 & 100.0 & 13 & 100.0 & 80 & 100.0 \\
\hline $\begin{array}{l}\text { Assaulted Someone } \\
\text { with Friends }\end{array}$ & & & & & & & & & & \\
\hline No & 16 & 36.4 & 2 & 15.4 & 4 & 36.4 & 4 & 30.8 & 26 & 32.1 \\
\hline Yes & 28 & 63.6 & 11 & 84.6 & 7 & 63.6 & 9 & 69.2 & 55 & 67.9 \\
\hline Total & 44 & 100.0 & 13 & 100.0 & 11 & 100.0 & 13 & 100.0 & 81 & 100.0 \\
\hline $\begin{array}{l}\text { With a Group of } \\
\text { Friends, Fought with } \\
\text { Others }\end{array}$ & & & & & & & & & & \\
\hline No & 20 & 38.5 & 2 & 13.3 & 4 & 30.8 & 3 & 23.1 & 29 & 31.2 \\
\hline Yes & 32 & 61.5 & 13 & 86.7 & 9 & 69.2 & 10 & 76.9 & 64 & 68.8 \\
\hline Total & 52 & 100.0 & 15 & 100.0 & 13 & 100.0 & 13 & 100.0 & 93 & 100.0 \\
\hline
\end{tabular}

Source of data: Youth Offender Interview.

1 “Other Ethnic Background” includes Middle Eastern, Hispanic, African, Mulatto, and Asian. 
When asked if they had ever threatened someone with a weapon, 59\% of all youth stated that they had. Participants in the first or second generation immigrant, Caucasian group were most likely to have threatened someone with a weapon (77.8\%), while youth in the in the first or second generation immigrant, other ethnic background group were least likely to have done this (33.3\%). A substantial majority of youth in all groups indicated that they had ever assaulted or hurt someone (87.1\%), and slightly less than one-third (61.2\%) stated that they had assaulted or hurt someone with a weapon. When asked if they had ever assaulted someone with friends, approximately two-thirds (67.9\%) stated that they had; this behaviour was most common in the Native/Métis group (84.6\%). When asked if they had fought with others with a group of friends, the prevalence of this behaviour ranged from $61.5 \%$ in the Canadian born/parents Canadian born group to $86.7 \%$ in the Native/Métis group.

Youth probation files contained considerable information regarding participants’ mental health status and any mental health diagnoses that they had received; these findings are summarized in Table 3. Several of these characteristics differed significantly across the immigration groups. Almost one-half of all youth (47.1\%) had ever had a psychological assessment; 76.9\% of youth in the Native/Métis group had received an assessment, followed by $58.3 \%$ of youth in the first or second generation immigrant, Caucasian group, $44.9 \%$ of youth in the Canadian born/parents Canadian born group, and only $9.1 \%$ of participants in the first or second generation immigrant, other ethnic background group. The majority of all youth (84.7\%) had received counselling, ranging from $54.5 \%$ of youth in the first or second generation immigrant, other ethnic background group to $100 \%$ of youth in the first or second generation immigrant, Caucasian group.

Table 3. Mental Health Characteristics of Youth by Immigrant Status

\begin{tabular}{|c|c|c|c|c|c|c|c|c|c|c|}
\hline \multirow{3}{*}{$\begin{array}{l}\text { Mental Health } \\
\text { Characteristics }\end{array}$} & \multicolumn{8}{|c|}{ Immigrant Status } & \multicolumn{2}{|c|}{ Total } \\
\hline & \multicolumn{2}{|c|}{$\begin{array}{c}\text { Canadian } \\
\text { Born, } \\
\text { Parent(s) } \\
\text { Canadian } \\
\text { Born } \\
\end{array}$} & \multicolumn{2}{|c|}{ Native/Métis } & \multicolumn{2}{|c|}{$\begin{array}{c}\mathbf{1}^{\text {st }} \text { or } 2^{\text {nd }} \\
\text { Generation } \\
\text { Immigrant, } \\
\text { Caucasian }\end{array}$} & \multicolumn{2}{|c|}{$\begin{array}{l}1^{\text {st }} \text { or } 2^{\text {nd }} \\
\text { Generation } \\
\text { Immigrant, } \\
\text { Other Ethnic } \\
\text { Background } \\
\end{array}$} & \multirow[t]{2}{*}{$n$} & \multirow[t]{2}{*}{$\%$} \\
\hline & $n$ & $\%$ & $n$ & $\%$ & $n$ & $\%$ & $n$ & $\%$ & & \\
\hline $\begin{array}{l}\text { Ever Had a } \\
\text { Psychological }^{2} \\
\text { Assessment }^{2}\end{array}$ & & & & & & & & & & \\
\hline No & 27 & 55.1 & 3 & 23.1 & 5 & 41.7 & 10 & 90.9 & 45 & 52.9 \\
\hline Yes & 22 & 44.9 & 10 & 76.9 & 7 & 58.3 & 1 & 9.1 & 40 & 47.1 \\
\hline Total & 49 & 100.0 & 13 & 100.0 & 12 & 100.0 & 11 & 100.0 & 85 & 100.0 \\
\hline $\begin{array}{l}\text { Ever Received } \\
\text { Counselling }\end{array}$ & & & & & & & & & & \\
\hline No & 4 & 8.2 & 4 & 30.8 & 0 & 0.0 & 5 & 45.5 & 13 & 15.3 \\
\hline Yes & 45 & 91.8 & 9 & 69.2 & 12 & 100.0 & 6 & 54.5 & 72 & 84.7 \\
\hline Total & 49 & 100.0 & 13 & 100.0 & 12 & 100.0 & 11 & 100.0 & 85 & 100.0 \\
\hline
\end{tabular}




\begin{tabular}{|c|c|c|c|c|c|c|c|c|c|c|}
\hline \multirow{4}{*}{$\begin{array}{l}\text { Diagnosis of Mental } \\
\text { Health Problems }{ }^{4} \\
\text { No } \\
\text { Yes } \\
\text { Total }\end{array}$} & \multirow{4}{*}{$\begin{array}{l}23 \\
29 \\
52\end{array}$} & \multirow{4}{*}{$\begin{array}{r}44.2 \\
55.8 \\
100.0\end{array}$} & \multirow{3}{*}{$\begin{array}{r}4 \\
10\end{array}$} & \multirow{3}{*}{$\begin{array}{l}28.6 \\
71.4\end{array}$} & \multirow[b]{2}{*}{4} & \multirow[b]{2}{*}{30.8} & \multirow[b]{2}{*}{12} & \multirow[b]{2}{*}{92.3} & \multirow[b]{2}{*}{43} & \multirow[b]{2}{*}{46.7} \\
\hline & & & & & & & & & & \\
\hline & & & & & 9 & 69.2 & 1 & 7.7 & 49 & 53.3 \\
\hline & & & 14 & 100.0 & 13 & 100.0 & 13 & 100.0 & 92 & 100.0 \\
\hline \multicolumn{11}{|l|}{ Depression $^{5}$} \\
\hline No & 38 & 74.5 & 12 & 92.3 & 6 & 50.0 & 12 & 92.3 & 68 & 76.4 \\
\hline Yes & 13 & 25.5 & 1 & 7.7 & 6 & 50.0 & 1 & 7.7 & 21 & 23.6 \\
\hline Total & 51 & 100.0 & 13 & 100.0 & 12 & 100.0 & 13 & 100.0 & 89 & 100.0 \\
\hline \multicolumn{11}{|l|}{\begin{tabular}{|l|} 
Learning Disability \\
\end{tabular}} \\
\hline No & 42 & 82.4 & 11 & 84.6 & 10 & 83.3 & 13 & 100.0 & 76 & 85.4 \\
\hline Yes & 9 & 17.6 & 2 & 15.4 & 2 & 16.7 & 0 & 0.0 & 13 & 14.6 \\
\hline Total & 51 & 100.0 & 13 & 100.0 & 12 & 100.0 & 13 & 100.0 & 89 & 100.0 \\
\hline \multicolumn{11}{|l|}{$\begin{array}{l}\text { Attention Deficit } \\
\text { Disorder/Attention } \\
\text { Deficit Hyperactivity } \\
\text { Disorder }^{6}\end{array}$} \\
\hline No & 32 & 62.7 & 6 & 46.2 & 5 & 41.7 & 12 & 92.3 & 55 & 61.8 \\
\hline Yes & 19 & 37.3 & 7 & 53.8 & 7 & 58.3 & 1 & 7.7 & 34 & 38.2 \\
\hline Total & 51 & 100.0 & 13 & 100.0 & 12 & 100.0 & 13 & 100.0 & 89 & 100.0 \\
\hline \multicolumn{11}{|l|}{\begin{tabular}{|l} 
Conduct Disorder \\
\end{tabular}} \\
\hline No & 34 & 66.7 & 9 & 69.2 & 8 & 66.7 & 12 & 92.3 & 63 & 70.8 \\
\hline Yes & 17 & 33.3 & 4 & 30.8 & 4 & 33.3 & 1 & 7.7 & 26 & 29.2 \\
\hline Total & 51 & 100.0 & 13 & 100.0 & 12 & 100.0 & 13 & 100.0 & 89 & 100.0 \\
\hline \multicolumn{11}{|l|}{$\begin{array}{l}\text { Fetal Alcohol } \\
\text { Spectrum Disorder }\end{array}$} \\
\hline No & 50 & 98.0 & 12 & 92.3 & 9 & 75.0 & 13 & 100.0 & 84 & 94.4 \\
\hline Yes & 1 & 2.0 & 1 & 7.7 & 3 & 25.0 & 0 & 0.0 & 5 & 5.6 \\
\hline Total & 51 & 100.0 & 13 & 100.0 & 12 & 100.0 & 13 & 100.0 & 89 & 100.0 \\
\hline \multicolumn{11}{|l|}{\begin{tabular}{|l|} 
Anger Issues \\
\end{tabular}} \\
\hline No & 44 & 86.3 & 11 & 84.6 & 8 & 66.7 & 13 & 100.0 & 76 & 85.4 \\
\hline Yes & 7 & 13.7 & 2 & 15.4 & 4 & 33.3 & 0 & 0.0 & 13 & 14.6 \\
\hline Total & 51 & 100.0 & 13 & 100.0 & 12 & 100.0 & 13 & 100.0 & 89 & 100.0 \\
\hline
\end{tabular}

Sources of data: Youth Offender Interview and Youth Probation File Review.

1 "Other Ethnic Background" includes Middle Eastern, Hispanic, African, Mulatto, and Asian.

${ }^{2} X^{2}(3)=11.7, p<.01$.

${ }^{3} X^{2}(3)=14.2, p<.01$.

${ }^{4} X^{2}(3)=14.2, p<.01$.

${ }^{5} X^{2}(3)=8.4, p<.05$.

${ }^{6} X^{2}(3)=8.6, p<.05$.

${ }^{7} X^{2}(3)=10.7, p<.05$. 
Just over one-half of the total sample had received a diagnosis of mental health problems (53.3\%); this ranged from $7.7 \%$ of participants in the first or second generation immigrant, other ethnic background group to $71.4 \%$ of youth in the Native/Métis group. Almost one-quarter of the total sample had received a diagnosis of depression (23.6\%); a depression diagnosis was most common in the first or second generation immigrant, Caucasian group (50\%) and least common in the Native/Métis and first or second generation immigrant, other ethnic background groups (7.7\% each). The prevalence of a diagnosis of attention deficit disorder/attention deficit hyperactivity disorder (ADD/ADHD) also differed significantly across immigration status groups. While the overall prevalence of an ADD/ADHD diagnosis was 38.2\%, when examined by group, the prevalence ranged from $7.7 \%$ for youth in the first or second generation immigrant, other ethnic background group to $58.3 \%$ in the first or second generation immigrant, Caucasian group. Finally, the prevalence of Fetal Alcohol Spectrum Disorder (FASD) also differed significantly across immigration status groups; however, the overall prevalence of FASD was quite low (5.6\%), so this finding should be interpreted with caution. The results indicated that $25 \%$ of youth in the first or second generation immigrant, Caucasian group had a diagnosis of FASD, compared to 7.7\% in the Native/Métis group, 2\% in the Canadian born/parents Canadian born group, and $0 \%$ in the first or second generation immigrant, other ethnic background group.

\section{Family Factors Domain}

Several potential risk and protective family factors were examined in relation to participants’ immigration status. Table 4 presents the findings for family characteristics. A significant relationship was found between having a history of being in foster care and immigration status. Almost one-third of the total sample (29\%) had a history of foster care. Native/Métis youth were substantially more likely to have been in foster care (60\%) than were youth in the first or second generation immigrant, Caucasian (30.8\%), the Canadian born/parents Canadian born (25\%), and the first or second generation immigrant, other ethnic background groups $(7.7 \%)$.

Whether youth had ever run away from home was also significantly related to immigration group. Over two-thirds of participants in the total sample (68.8\%) had run away from home; youth in the Canadian born/parents Canadian born (76.9\%) and the first or second generation immigrant, Caucasian groups $(76.9 \%)$ were most likely to have run away while youth in the first or second generation immigrant, other ethnic background group were least likely to have run away from home (38.5\%). Just over one-quarter of all youth reported that their parents were currently married (28.3\%); however, there were no significant differences across groups on this variable. Similarly, one-quarter of all participants stated that they were living with both parents at the time of their interview (25.8\%). 
International Journal of Child, Youth and Family Studies (2013) 1: 166-188

Table 4. Family Characteristics of Youth by Immigrant Status

\begin{tabular}{|c|c|c|c|c|c|c|c|c|c|c|}
\hline \multirow{3}{*}{ Family Characteristics } & \multicolumn{8}{|c|}{ Immigrant Status } & \multicolumn{2}{|c|}{ Total } \\
\hline & \multicolumn{2}{|c|}{$\begin{array}{l}\text { Canadian } \\
\text { Born, } \\
\text { Parent(s) } \\
\text { Canadian } \\
\text { Born }\end{array}$} & \multicolumn{2}{|c|}{ Native/Métis } & \multicolumn{2}{|c|}{$\begin{array}{l}\mathbf{1}^{\text {st }} \text { or } 2^{\text {nd }} \\
\text { Generation }^{\text {Immigrant, }} \\
\text { Caucasian }\end{array}$} & \multicolumn{2}{|c|}{$\begin{array}{l}1^{\text {st }} \text { or } 2^{\text {nd }} \\
\text { Generation } \\
\text { Immigrant, } \\
\text { Other Ethnic } \\
\text { Background }\end{array}$} & \multirow[t]{2}{*}{$n$} & \multirow[t]{2}{*}{$\%$} \\
\hline & $n$ & $\%$ & $n$ & $\%$ & $n$ & $\%$ & $n$ & $\%$ & & \\
\hline $\begin{array}{l}\text { Marital Status of } \\
\text { Parents }\end{array}$ & & & & & & & & & & \\
\hline Married & 14 & 27.5 & 3 & 20.0 & 5 & 38.5 & 4 & 30.8 & 26 & 28.3 \\
\hline Other $^{2}$ & 37 & 72.5 & 12 & 80.0 & 8 & 61.5 & 9 & 69.2 & 66 & 71.7 \\
\hline Total & 51 & 100.0 & 15 & 100.0 & 13 & 100.0 & 13 & 100.0 & 92 & 100.0 \\
\hline $\begin{array}{l}\text { Current Living } \\
\text { Arrangements at Time } \\
\text { of Interview }\end{array}$ & & & & & & & & & & \\
\hline Both parents & 12 & 23.1 & 3 & 20.0 & 4 & 30.8 & 5 & 38.5 & 24 & 25.8 \\
\hline Other $^{3}$ & 40 & 76.9 & 12 & 80.0 & 9 & 69.2 & 8 & 61.5 & 69 & 74.2 \\
\hline Total & 52 & 100.0 & 15 & 100.0 & 13 & 100.0 & 13 & 100.0 & 93 & 100.0 \\
\hline $\begin{array}{l}\text { Contact with Child } \\
\text { Welfare }\end{array}$ & & & & & & & & & & \\
\hline No & 26 & 50.0 & 6 & 40.0 & 4 & 30.8 & 7 & 53.8 & 43 & 46.2 \\
\hline Yes & 26 & 50.0 & 9 & 60.0 & 9 & 69.2 & 6 & 46.2 & 50 & 53.8 \\
\hline Total & 52 & 100.0 & 15 & 100.0 & 13 & 100.0 & 13 & 100.0 & 93 & 100.0 \\
\hline History of Foster Care ${ }^{4}$ & 39 & 750 & 6 & 400 & 9 & 697 & 12 & 92 3 & 66 & 710 \\
\hline Yes & 13 & 25.0 & 9 & 60.0 & 4 & 30.8 & $\begin{array}{r}12 \\
1\end{array}$ & 7.7 & 27 & 29.0 \\
\hline Total & 52 & 100.0 & 15 & 100.0 & 13 & 100.0 & 13 & 100.0 & 93 & 100.0 \\
\hline $\begin{array}{l}\text { History of Residence in } \\
\text { Group Home }\end{array}$ & & & & & & & & & & \\
\hline No & 26 & 50.0 & 9 & 60.0 & 5 & 38.5 & 8 & 61.5 & 48 & 51.6 \\
\hline Yes & 26 & 50.0 & 6 & 40.0 & 8 & 61.5 & 5 & 38.5 & 45 & 48.4 \\
\hline Total & 52 & 100.0 & 15 & 100.0 & 13 & 100.0 & 13 & 100.0 & 93 & 100.0 \\
\hline $\begin{array}{l}\text { Ever Run Away from } \\
\text { Home }^{5}\end{array}$ & & & & & & & & & & \\
\hline No & 12 & 23.1 & 6 & 40.0 & 3 & 23.1 & 8 & 61.5 & 29 & 31.2 \\
\hline Yes & 40 & 76.9 & 9 & 60.0 & 10 & 76.9 & 5 & 38.5 & 64 & 68.8 \\
\hline Total & 52 & 100.0 & 15 & 100.0 & 13 & 100.0 & 13 & 100.0 & 93 & 100.0 \\
\hline
\end{tabular}

Sources of data: Youth Offender Interview and Youth Probation File Review.

1 “Other Ethnic Background” includes Middle Eastern, Hispanic, African, Mulatto, and Asian.

2 "Other" includes Never married/common law, Separated, Divorced, and Widowed.

3 “Other” includes One parent/siblings, Extended family, Foster/group home, Independent/partner, Incarcerated, and Other.

${ }^{4} X^{2}(3)=10.3, p<.05$.

${ }^{5} X^{2}(3)=8.2, p<.05$. 
Just over one-half of all youth reported having contact with child welfare (53.8\%); while not statistically significant, participants in the first or second generation immigrant, Caucasian group were most likely to have had child welfare contact (69.2\%) while youth in the first or second generation immigrant, other ethnic background group were least likely to have had contact with child welfare (46.2\%). Finally, when asked if they had ever lived in a group home, almost one-half of the entire sample indicated that they had (48.4\%).

Table 5 presents the relationship between the exposure to various adverse family experiences and immigration status. The only variable that differed significantly across groups was whether there was criminal involvement by immediate family members of the youth. Onefifth of all youth reported criminal involvement by family members (19.8\%). Youth in the Native/Métis group were most likely to report criminal involvement by family members (42.9\%) while no youth in the first or second generation immigrant, other ethnic background group reported this. While not statistically significant, youth in the Native/Métis group were substantially more likely to have been exposed to domestic violence (78.6\%) than were youth in the first or second generation immigrant, other ethnic background group (30.8\%). Over one-third of youth had a history of being physically abused (36.3\%). Youth in the first or second generation immigrant, Caucasian group were most likely to have experienced physical abuse (53.8\%) while youth in the first or second generation immigrant, other ethnic background group were least likely to have been physically abused (15.4\%). A total of $16.5 \%$ of all youth had confirmed or suspected sexual abuse; the prevalence of sexual abuse ranged from $35.7 \%$ of youth in the Native/Métis group to $7.7 \%$ in each of the first or second generation immigrant, Caucasian and the first or second generation immigrant, other ethnic background groups.

Table 5. Exposure of Youth to Various Adverse Family Experiences by Immigrant Status

\begin{tabular}{|c|c|c|c|c|c|c|c|c|c|c|}
\hline \multirow{3}{*}{ Family Experiences } & \multicolumn{8}{|c|}{ Immigrant Status } & \multicolumn{2}{|c|}{ Total } \\
\hline & \multicolumn{2}{|c|}{$\begin{array}{c}\text { Canadian } \\
\text { Born, } \\
\text { Parent(s) } \\
\text { Canadian } \\
\text { Born } \\
\end{array}$} & \multicolumn{2}{|c|}{ Native/Métis } & \multicolumn{2}{|c|}{$\begin{array}{l}1^{\text {st }} \text { or } 2^{\text {nd }} \\
\text { Generation } \\
\text { Immigrant, } \\
\text { Caucasian }\end{array}$} & \multicolumn{2}{|c|}{$\begin{array}{l}1^{\text {st }} \text { or } 2^{\text {nd }} \\
\text { Generation } \\
\text { Immigrant, } \\
\text { Other Ethnic } \\
\text { Background }\end{array}$} & \multirow[t]{2}{*}{$\mathbf{n}$} & \multirow[t]{2}{*}{$\%$} \\
\hline & $\mathbf{n}$ & $\%$ & $\mathbf{n}$ & $\%$ & $\mathbf{n}$ & $\%$ & $\mathbf{n}$ & $\%$ & & \\
\hline Domestic Violence & & & & & & & & & & \\
\hline No & 22 & 42.3 & 3 & 21.4 & 6 & 46.2 & 9 & 69.2 & 40 & 43.5 \\
\hline Yes & 30 & 57.7 & 11 & 78.6 & 7 & 53.8 & 4 & 30.8 & 52 & 56.5 \\
\hline Total & 52 & 100.0 & 14 & 100.0 & 13 & 100.0 & 13 & 100.0 & 92 & 100.0 \\
\hline Substance Abuse & & & & & & & & & & \\
\hline No & 24 & 47.1 & 6 & 42.9 & 8 & 61.5 & 11 & 84.6 & 49 & 53.8 \\
\hline Yes & 27 & 52.9 & 8 & 57.1 & 5 & 38.5 & 2 & 15.4 & 42 & 46.2 \\
\hline Total & 51 & 100.0 & 14 & 100.0 & 13 & 100.0 & 13 & 100.0 & 91 & 100.0 \\
\hline Physical Abuse & & & & & & & & & & \\
\hline No & 30 & 58.8 & 11 & 78.6 & 6 & 46.2 & 11 & 84.6 & 58 & 63.7 \\
\hline Yes & 21 & 41.2 & 3 & 21.4 & 7 & 53.8 & 2 & 15.4 & 33 & 36.3 \\
\hline Total & 51 & 100.0 & 14 & 100.0 & 13 & 100.0 & 13 & 100.0 & 91 & 100.0 \\
\hline
\end{tabular}




\begin{tabular}{|l|r|r|r|r|r|r|r|r|r|r||}
\hline $\begin{array}{l}\text { Emotional, Mental or } \\
\text { Verbal Abuse }\end{array}$ & & & & & & & & & & \\
No & 34 & 66.7 & 10 & 71.4 & 10 & 76.9 & 12 & 92.3 & 66 & 72.5 \\
Yes & 17 & 33.3 & 4 & 28.6 & 3 & 23.1 & 1 & 7.7 & 25 & 27.5 \\
Total & 51 & 100.0 & 14 & 100.0 & 13 & 100.0 & 13 & 100.0 & 91 & 100.0 \\
\hline Sexual Abuse & & & & & & & & & & \\
No & 43 & 84.3 & 9 & 64.3 & 12 & 92.3 & 12 & 92.3 & 76 & 83.5 \\
Yes & 8 & 15.7 & 5 & 35.7 & 1 & 7.7 & 1 & 7.7 & 15 & 16.5 \\
Total & 51 & 100.0 & 14 & 100.0 & 13 & 100.0 & 13 & 100.0 & 91 & 100.0 \\
\hline Criminal Involvement & & & & & & & & & & \\
by Immediate Family & & & & & & & & & & \\
Member(s) $^{2}$ & 43 & 84.3 & 8 & 57.1 & 9 & 69.2 & 13 & 100.0 & 73 & 80.2 \\
No & 8 & 15.7 & 6 & 42.9 & 4 & 30.8 & 0 & 0.0 & 18 & 19.8 \\
Yes & 51 & 100.0 & 14 & 100.0 & 13 & 100.0 & 13 & 100.0 & 91 & 100.0 \\
Total
\end{tabular}

Sources of data: Youth Offender Interview and Youth Probation File Review.

1 “Other Ethnic Background" includes Middle Eastern, Hispanic, African, Mulatto, and Asian.

${ }^{2} X^{2}(3)=9.4, p<.05$.

\section{Peer Group Factors Domain}

Two factors within the peer group domain were significantly related to immigration status: whether the youth was involved in lessons in dance, music, hobbies, or other non-sport activities $\left(X^{2}(3)=8.9, p<.05\right)$ and whether they reported that they were a gang member at the time of the interview $\left(X^{2}(3)=8.0, p<.05\right)$. However, only three youth in the entire sample indicated participating in lessons, so this finding should be interpreted with caution. Two of these three youth were in the first or second generation immigrant, other ethnic background group, while the other youth was in the Native/Métis group. With regard to the gang membership variable, $14.4 \%$ of youth in all groups were gang members at the time of the interview. Participants in the Native/Métis group were most likely to be gang members (33.3\%), followed by youth in the first or second generation immigrant, other ethnic background group (23.1\%) and the Canadian born/parents Canadian born group (10.2\%). No youth in the first or second generation immigrant, Caucasian group were gang members at the time of the interview. One-half of all the youth (50.5\%) indicated that some of their friends were gang members. Although not statistically significant, Native/Métis youth were most likely to report that their friends were members of a gang (66.7\%) while youth in the first or second generation immigrant, Caucasian (46.2\%) and the Canadian born/parents Canadian born (46\%) groups were least likely to report this. Over one-third of all participants reported having ever been a member of a gang (37.8\%).

\section{School Factors Domain}

Table 6 presents the relationship between several school factors and immigration status. 
International Journal of Child, Youth and Family Studies (2013) 1: 166-188

Table 6. School-related Characteristics of Youth by Immigrant Status

\begin{tabular}{|c|c|c|c|c|c|c|c|c|c|c|}
\hline \multirow{3}{*}{$\begin{array}{c}\text { School } \\
\text { Characteristics }\end{array}$} & \multicolumn{8}{|c|}{ Immigrant Status } & \multicolumn{2}{|c|}{ Total } \\
\hline & \multicolumn{2}{|c|}{$\begin{array}{c}\text { Canadian } \\
\text { Born, } \\
\text { Parent(s) } \\
\text { Canadian } \\
\text { Born }\end{array}$} & \multicolumn{2}{|c|}{ Native/Métis } & \multicolumn{2}{|c|}{$\begin{array}{l}1^{\text {st }} \text { or } 2^{\text {nd }} \\
\text { Generation } \\
\text { Immigrant, } \\
\text { Caucasian }\end{array}$} & \multicolumn{2}{|c|}{$\begin{array}{l}1^{\text {st }} \text { or } 2^{\text {nd }} \\
\text { Generation } \\
\text { Immigrant, } \\
\text { Other Ethnic } \\
\text { Background }\end{array}$} & \multirow[t]{2}{*}{$n$} & \multirow[t]{2}{*}{$\%$} \\
\hline & $n$ & $\%$ & $n$ & $\%$ & $n$ & $\%$ & $n$ & $\%$ & & \\
\hline \multicolumn{11}{|c|}{$\begin{array}{l}\text { School Status at Time of } \\
\text { Interview }^{2}\end{array}$} \\
\hline Attending & 30 & 57.7 & 9 & 60.0 & 10 & 76.9 & 13 & 100.0 & 62 & 66.7 \\
\hline Not attending & 22 & 42.3 & 6 & 40.0 & 3 & 23.1 & 0 & 0.0 & 31 & 33.3 \\
\hline Total & 52 & 100.0 & 15 & 100.0 & 13 & 100.0 & 13 & 100.0 & 93 & 100.0 \\
\hline \multicolumn{11}{|l|}{$\begin{array}{l}\text { Considered Dropping } \\
\text { Out of School }\end{array}$} \\
\hline No & 9 & 30.0 & 5 & 55.6 & 3 & 30.0 & 5 & 38.5 & 22 & 35.5 \\
\hline Yes & 21 & 70.0 & 4 & 44.4 & 7 & 70.0 & 8 & 61.5 & 40 & 64.5 \\
\hline Total & 30 & 100.0 & 9 & 100.0 & 10 & 100.0 & 13 & 100.0 & 62 & 100.0 \\
\hline \multicolumn{11}{|l|}{$\begin{array}{l}\text { Ever Been Suspended } \\
\text { from School }^{3}\end{array}$} \\
\hline No & 7 & 23.3 & 0 & 0.0 & 1 & 10.0 & 2 & 15.4 & 10 & 16.1 \\
\hline Yes & 23 & 76.7 & 9 & 100.0 & 9 & 90.0 & 11 & 84.6 & 52 & 83.9 \\
\hline Total & 30 & 100.0 & 9 & 100.0 & 10 & 100.0 & 13 & 100.0 & 62 & 100.0 \\
\hline \multicolumn{11}{|l|}{$\begin{array}{l}\text { Ever Been Bullied in } \\
\text { School }\end{array}$} \\
\hline No & 31 & 59.6 & 6 & 40.0 & 7 & 53.8 & 9 & 69.2 & 53 & 57.0 \\
\hline Yes & 21 & 40.4 & 9 & 60.0 & 6 & 46.2 & 4 & 30.8 & 40 & 43.0 \\
\hline Total & 52 & 100.0 & 15 & 100.0 & 13 & 100.0 & 13 & 100.0 & 93 & 100.0 \\
\hline \multicolumn{11}{|l|}{$\begin{array}{l}\text { Ever Been in Fights at } \\
\text { School }\end{array}$} \\
\hline No & 7 & 13.5 & 2 & 13.3 & 1 & 7.7 & 0 & 0.0 & 10 & 10.8 \\
\hline Yes & 45 & 86.5 & 13 & 86.7 & 12 & 92.3 & 13 & 100.0 & 83 & 89.2 \\
\hline Total & 52 & 100.0 & 15 & 100.0 & 13 & 100.0 & 13 & 100.0 & 93 & 100.0 \\
\hline \multicolumn{11}{|c|}{$\begin{array}{l}\text { Ever Taken a Weapon to } \\
\text { School }\end{array}$} \\
\hline No & 29 & 55.8 & 5 & 33.3 & 6 & 46.2 & 8 & 61.5 & 48 & 51.6 \\
\hline Yes & 23 & 44.2 & 10 & 66.7 & 7 & 53.8 & 5 & 38.5 & 45 & 48.4 \\
\hline Total & 52 & 100.0 & 15 & 100.0 & 13 & 100.0 & 13 & 100.0 & 93 & 100.0 \\
\hline \multicolumn{11}{|c|}{$\begin{array}{l}\text { Ever Used a Weapon at } \\
\text { School }^{4}\end{array}$} \\
\hline No & 17 & 77.3 & 7 & 70.0 & 5 & 83.3 & 4 & 100.0 & 33 & 78.6 \\
\hline Yes & 5 & 22.7 & 3 & 30.0 & 1 & 16.7 & 0 & 0.0 & 9 & 21.4 \\
\hline Total & 22 & 100.0 & 10 & 100.0 & 6 & 100.0 & 4 & 100.0 & 42 & 100.0 \\
\hline \multicolumn{11}{|l|}{ Gangs at School } \\
\hline No & 26 & 52.0 & 9 & 64.3 & 6 & 50.0 & 8 & 61.5 & 49 & 55.1 \\
\hline Yes & 24 & 48.0 & 5 & 35.7 & 6 & 50.0 & 5 & 38.5 & 40 & 44.9 \\
\hline Total & 50 & 100.0 & 14 & 100.0 & 12 & 100.0 & 13 & 100.0 & 89 & 100.0 \\
\hline
\end{tabular}


International Journal of Child, Youth and Family Studies (2013) 1: 166-188

The only variable that differed significantly across groups was school status at the time of the interview. Two-thirds of all participants (66.7\%) were attending school at the time of the interview. All youth in the first or second generation immigrant, other ethnic background group were attending school, compared to $76.9 \%$ of youth in the first or second generation immigrant, Caucasian group, $60 \%$ of Native/Métis youth, and $57.7 \%$ of participants in the Canadian born/parents Canadian born group.

The majority of youth who were attending school at the time of the interview reported that they had considered dropping out of school (64.5\%), and the substantial majority of all youth who were attending school reported that they had ever received a school suspension (83.9\%). When asked if they had ever been bullied in school, 43\% indicated that they had and almost all youth (89.2\%) reported that they had been in fights at school.

When asked if they had ever taken a weapon to school, almost one-half of all participants indicated that they had (48.4\%). Native/Métis youth were most likely to have taken a weapon to school (66.7\%), while youth in the first or second generation immigrant, other ethnic background group were least likely to have done this (38.5\%). Just over one-fifth of participants who had taken a weapon to school reported that they had used it (21.4\%). This ranged from $30 \%$ of Native/Métis youth to no youth in the first or second generation immigrant, other ethnic background group. When asked if there are gangs at their school, $44.9 \%$ of all participants indicated that there are.

\section{Community Factors Domain}

Four community-related variables were examined in relation to participants' immigration status: feelings of safety in the community; ever carried a weapon in the community; ever used a weapon in the community; and whether there are gangs in the community. None of these factors were found to be significantly related to the youths' immigration group. The majority of participants reported that they feel safe in their community (80.6\%). When asked if they had ever carried a weapon in their community, $44.1 \%$ of youth indicated that they had. Just over one-half of Native/Métis youth and youth in the first or second generation immigrant, Caucasian group (53.3\% and 53.8\%, respectively) had carried a weapon in their community. Youth in the first or second generation immigrant, other ethnic background group were least likely to report carrying a weapon in their community (30.8\%). Youth who had carried a weapon in their community were asked if they had ever used it, and 55\% stated that they had. Youth in the Canadian born/parents Canadian born group were most likely to state that they had used a weapon in their community (63.6\%), while participants in the first or second generation immigrant, other ethnic background group were least likely to have used a weapon (33.3\%).

Finally, just over one-half of all participants stated that there are gangs in their community (51.1\%). Youth in the Native/Métis group were most likely to report gangs in their community (80\%), while youth in the first or second generation immigrant, Caucasian group were least likely to state that there are gangs in their community (38.5\%). 
International Journal of Child, Youth and Family Studies (2013) 1: 166-188

\section{Discussion}

A number of Canadian and American authors (e.g., Choi et al., 2005; Powell, Perreira, \& Harris, 2010; Wortley, 2003) have emphasized the importance of examining risk and protective factors among ethnic and immigrant populations. Given Canada’s unique ethnic diversity, Canadian research in this area is imperative to ensure appropriate and effective policy and program development. This study contributes to a small but growing body of literature in Canada attempting to address the root causes of crime and victimization among these populations.

\section{Risk and Protective Factors}

When examining these risk and protective factors by ethnic and immigrant groups, a number of notable patterns emerged. Overall, the analyses did not reveal many instances where statistically significant differences in occurrence existed between the groups. Though the small sample sizes may be partially responsible, the findings are in line with Rojas and Gretton's (2007) observation that minority and non-minority youth generally display the same or similar risk factors. However, those factors that were found to vary significantly by immigrant group are important to note, and in line with the literature.

The literature suggests a particularly high rate of substance abuse among Aboriginal youth offenders (Rojas \& Gretton, 2007; Yessine \& Bonta, 2009), which was confirmed by the analyses. In addition, the literature also suggests a high incidence of mental health issues among Native and Métis youth, which was confirmed in the analyses, with Native and Métis youth having the highest incidence of a mental health diagnosis. However, while Native and Métis youth were most likely to have a mental health diagnosis, they were not as likely to have received counselling. Native and Métis youth were most likely to possess a number of other individual risk factors related to delinquent behaviour. The incidence of property crimes, particularly theft, was often highest among Aboriginal youth, with this group being significantly more likely to break into a house.

Findings related to family risk factors for Aboriginal youth were also in line with the literature. The analyses demonstrated that Native and Métis youth were among the most likely to have a history of child welfare involvement, particularly foster care placement. This is consistent with the findings in the literature related to caregiver inconsistency (Rojas \& Gretton, 2007; Yessine \& Bonta, 2009). Though the literature also suggests that multiple caregivers among extended family is an important value in Aboriginal culture, the involvement with the child welfare system that is evident among this sample of Native and Métis youth indicates that extended family may not be predominant in their lives. Exposure to family violence and familial substance abuse, as well as having family members with criminal involvement, were also more common among the Aboriginal youth in the sample, consistent with Rojas and Gretton's (2007) findings. In addition, though the differences were not significant, Native and Métis youth had the highest incidence of suspected or confirmed sexual abuse in the sample.

Bracken et al. (2009) discuss the generational impact of residential schools, and the role this legacy plays in gang involvement among Aboriginal youth. The desire for support and acceptance on the part of Aboriginal youth offenders, who frequently live in poverty and lack 
family support, is often fulfilled in gangs. The study results support this hypothesis, with Aboriginal youth being most likely to be involved with gangs, and significantly more likely to be gang members at the time they were interviewed. Further, analyses revealed that $80 \%$ of Native and Métis youth report the presence of gangs in their community, the highest of all groups. The low incidence of involvement in extracurricular activities suggests that Native and Métis youth are not finding support and acceptance in pro-social ways. This, combined with the findings related to familial risk factors, suggest support for Bracken et al.’s (2009) assertion. Future research is needed to more closely examine the interaction between family risk factors, poverty, and gang involvement.

The available literature also cites poor educational attainment as a possible risk factor among Aboriginal youth offenders (Rojas \& Gretton, 2007). Findings from the current study support this suggestion, with the Native and Métis youth being significantly less likely than immigrant youth to be in school at the time they were interviewed; however, Native and Métis youth were also less likely than youth in all other groups to consider dropping out. The Native and Métis youth in the sample struggled with behavioural issues in school, being more likely than youth in other groups to be suspended and use a weapon at school. However, Native and Métis youth also had the highest incidence of being bullied in school. The combination of these factors suggests a negative spiral in the educational experience of Native and Métis youth, and potentially, a cycle of learned helplessness.

Findings of significant risk factors among Native and Métis youth are coupled with the low incidence of various protective factors. Although the differences were not statistically significant, Native and Métis youth were the least likely to have married parents. They were also the least likely to be living with both parents at the time of their interview. Native and Métis youth also had a very low incidence of involvement in extracurricular activities.

Though Native and Métis youth were found to be significantly more likely to display certain risk factors, first or second generation Caucasian immigrant youth and first or second generation immigrant youth of other ethnic backgrounds displayed some of their own unique risk and protective factors as well. Findings from the study reveal that with regard to individual risk factors, Caucasian immigrant youth are slightly more likely to engage in the use and exchange of illegal drugs, and are substantially more likely to have substance abuse issues than immigrant youth of other ethnic backgrounds, $77 \%$ versus $23 \%$. Furthermore, while Caucasian immigrant youth had slightly higher rates of delinquent behaviour involving property damage, immigrant youth of other ethnic backgrounds had higher rates of theft under and over \$50. This may indicate support for the hypothesis that immigrant youth from certain backgrounds commit economic crimes due to poverty and/or the absence of supervision and structure; however, more information on these factors is required to conclusively identify these relationships. The literature also suggests that the use of violence to resolve issues is a risk factor among immigrant youth (Rossiter \& Rossiter, 2009). Findings from the current study revealed that immigrant youth from other ethnic backgrounds had the highest rate of assault (100\%), while Caucasian immigrant youth had the highest rate of threatening someone with a weapon.

With regard to mental health, though there is little information in the literature, the current study revealed some notable patterns among immigrant youth. Immigrant youth from 
other ethnic backgrounds were the least likely to receive a psychological assessment, have a mental health diagnosis, or to have had counselling, with these findings being significant. In contrast, all immigrant Caucasian youth had received counselling and were among the most likely to have had a diagnosis of mental health problems, particularly depression, ADHD, and FASD. Though it is difficult to draw conclusions about this difference, it may be explained by differences in cultural norms and values regarding mental health. Future research is required to clarify mental health issues as a risk factor among immigrant and ethnic minority youth.

Regarding family factors, the literature has cited family poverty and a lack of parental supervision as possible risk factors for immigrant youth (Goodman \& Ruggiero, 2008; Rossiter \& Rossiter, 2009). Though information regarding family poverty was not available, analyses of available family factors revealed that youth in both immigrant groups were slightly more likely to have married parents and to live with both parents at the time of the interview, but that these rates were still quite low - less than $40 \%$ for both variables. Immigrant youth from other ethnic backgrounds were significantly less likely than all the other groups to have a history of foster care, and less likely to have had a history of residence in a group home or any contact with child welfare. They were also significantly less likely to run away from home than Caucasian immigrant youth, who had the highest rate among the groups. The greater likelihood of intact families and attachment to homes for immigrant youth from other backgrounds points to a possible protective factor. However, the rates of intact families are still quite low among all groups, which points to the potential for unsupervised time, and ultimately, the opportunity to offend.

In addition, immigrant youth from other ethnic backgrounds were most often the least likely to experience abuse in their families, and were significantly less likely to have family members involved in crime. The findings were similar for Caucasian immigrant youth, though the rate of criminal involvement by family members was significantly higher for these youth.

The literature warns of the high propensity for gang involvement among immigrant youth given the cultural isolation they may experience and their desire for acceptance and belonging, citing that approximately $82 \%$ of gang members are visible minorities (Rossiter \& Rossiter, 2009). Rossiter and Rossiter (2009) contend that a cultural disconnect may arise among immigrant youth, and peer influence may overcome familial influence. The findings related to peer factors from the current study reveal some interesting findings in this regard. Immigrant youth from other ethnic backgrounds were second to Native and Métis youth in being the most likely to be gang members at the time of their interview. Approximately half of the youth in both immigrant groups had friends who belonged to a gang. Though gang membership was relatively low among immigrant youth, the risk is present, particularly given findings related to extracurricular activities. Though immigrant youth from other ethnic backgrounds had the highest rate of involvement in organized activities, and were significantly more likely to be involved in non-sport activities and lessons, the rate of involvement in organized activities was only slightly over one-third, and only two youth were involved in non-sport activities. As suggested by Rossiter and Rossiter (2009), involvement in pro-social groups and activities often protects youth from the allure of gang involvement. 
With regard to school risk factors, the literature suggests that immigrant youth may face greater educational challenges than other youth, perhaps due to cultural differences and challenges in other areas of life, as well as the possibility of having English as a second language (Rossiter \& Rossiter, 2009; Goodman \& Ruggiero, 2008). Findings from the analyses revealed that immigrant youth were significantly more likely to be in school at the time of the interview as compared to Canadian and Native/Métis youth, with all of the immigrant youth from other ethnic backgrounds attending school. However, other school risk factors were present that may suggest educational struggles. Caucasian immigrant youth were the most likely to consider dropping out of school, followed closely by non-Caucasian immigrant youth, and both groups were more likely than Canadian youth to have been suspended. Youth in the immigrant groups also had the highest rates of getting into fights at school. Thus, though immigrant youth seem to demonstrate a willingness to attend school, which may act as a protective factor, findings would suggest a lack of attachment and behavioural issues.

Finally, with regard to community factors, the literature suggests that strong ties to and involvement in the community among immigrant youth acts as a protective factor (Choi et al., 2005; Rossiter \& Rossiter, 2009), fulfilling the sense of belonging that could be satisfied by gang involvement. Though the findings from analyses of community factors are mixed, a majority of immigrant youth from other ethnic backgrounds reported feeling safe in their communities, whereas Caucasian immigrant youth were the most likely to feel unsafe. Just over half of Caucasian immigrant youth carried a weapon in the community, compared to a third of immigrant youth of other ethnic backgrounds. Under half of both groups reported gangs in their community. Though few conclusions can be drawn from findings related to community, the literature suggests that increasing community protective factors decreases the propensity for crime. 
International Journal of Child, Youth and Family Studies (2013) 1: 166-188

\section{References}

Alberta Crime Reduction and Safe Communities Task Force. (2007). Keeping communities safe: Report and recommendations. Edmonton: Government of Alberta.

Bonta, J., LaPrairie, C., \& Wallace-Capretta, S. (1997). Risk prediction and re-offending: Aboriginal and non-Aboriginal offenders. Canadian Journal of Criminology and Criminal Justice, 39(2), 127-144.

Bracken, D. C., Deane, L., \& Morrissette, L. (2009). Desistance and social marginalization: The case of Canadian Aboriginal offenders. Theoretical Criminology, 13(61), 61-78.

Choi, Y., Harachi, T. W., Gillmore, M. R., \& Catalano R. F. (2005). Applicability of the social development model to urban minority youth: Examining the relationship between external constraints, family socialization, and problem behaviours. Journal of Research on Adolescence, 15(4), 505-534.

Goodman, A., \& Ruggiero, V. (2008). Crime, punishment, and ethnic minorities in England and Wales. Race/Ethnicity: Multidisciplinary Global Perspectives, (2)1, 53-68.

Government of Alberta. (2011). Alberta's crime prevention framework. Edmonton: Government of Alberta Safe Communities Secretariat.

MacRae, L. D., Bertrand, L. D., Paetsch, J. J., Hornick, J. P., \& DeGusti, B. (2009). A study of youth reoffending in Calgary. Prepared for the Alberta Law Foundation. Calgary, AB: Canadian Research Institute for Law and the Family.

Powell, D., Perreira, K. M., \& Harris, K. M. (2010). Trajectories of delinquency from adolescence to adulthood. Youth \& Society, 41(4), 275-502.

Rojas, E. Y., \& Gretton, H. M. (2007). Background, offence characteristics, and criminal outcomes of Aboriginal youth who sexually offend: A closer look at Aboriginal youth intervention needs. Sexual Abuse: A Journal of Research and Treatment, 19(3), 257-283.

Rossiter, M. J., \& Rossiter, K. R. (2009). Diamonds in the rough: Bridging gaps in supports for at-risk immigrant and refugee youth. International Migration and Immigration, 10(4), 409-429.

Wortley, S. (2003). Hidden intersections: Research on race, crime, and criminal justice in Canada. Canadian Ethnic Studies, 35(3), 99-117.

Yessine, A. K., \& Bonta, J. (2009). The offending trajectories of youthful Aboriginal offenders. Canadian Journal of Criminology and Criminal Justice, 51(4), 435-472. 